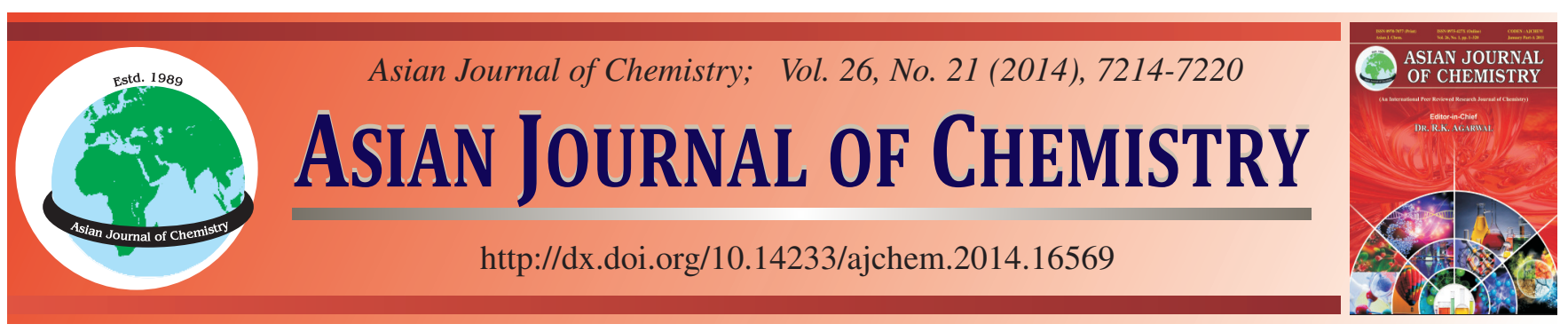

\title{
Optimization of Ultrasound-Assisted Extraction of Polysaccharides from Mulberry Leaves by Response Surface Methodology
}

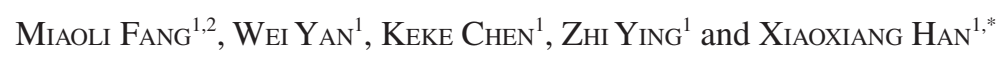

${ }^{1}$ Department of Applied Chemistry, College of Food Science \& Biotechnology Engineering, Zhejiang Gongshang University, Hangzhou 310035 , P.R. China

${ }^{2}$ Zhejiang Medical College, Hangzhou 310053, P.R. China

*Corresponding author: E-mail: hxx74@126.com

Received: 23 October 2013;

Accepted: 18 March 2014;

Published online: 30 September 2014;

AJC-16105

Response surface methodology was applied to optimize the ultrasound-assisted extraction of polysaccharides from mulberry leaves. A central-composite rotatory design (CCRD) was used for experimental design and analysis of the results to obtain the optimum extraction conditions. Based on the response surface methodology analysis, optimum conditions were: ratio of water to raw material 15:1, power of ultrasound $60 \mathrm{~W}$, extraction temperature $80^{\circ} \mathrm{C}$ and extraction time $20 \mathrm{~min}$. Under the optimized conditions, the experimental values were in close agreement with values predicted by the mathematical model. Compared with conventional solvent extraction, ultrasound-assisted extraction was a better method to extract polysaccharides. The crude polysaccharides prepared under optimum conditions contained $55.06 \%$ total sugar, $14.02 \%$ protein, $14.49 \%$ moisture and $17.48 \%$ ash.

Keywords: Mulberry leaves, Polysaccharides, Ultrasound-assisted extraction, Response surface methodology.

ᄂ - - - - - - - - - - - - - - - - - - - - - - - - -

\section{INTRODUCTION}

Mulberry, a member of the genus Morus of the family Moraceae, is found from subtropical regions of the Northern Hemisphere to the tropics of the Southern Hemisphere ${ }^{1}$. In most mulberry-growing countries, especially in China and India, mulberry is used to feed the silkworms (Bombyx mori L.) for its foliage. As a Chinese traditional herbal medicine, mulberry is also widely used to lower blood pressure ${ }^{2,3}$, cure or prevent diabetes ${ }^{4}$, treat fever, protect the liver, improve eyesight, strengthen joints and facilitate discharge of urine.

Polysaccharide from plant, epiphyte and animal extracts is an interesting source of additives for several industries, especially food and drug industry. Polysaccharides from mulberry leaves have significant antihyperglycemic activity and lower blood lipid $^{5,6}$. Therefore, discovery and evaluation of polysaccharides from the mulberry leaves as new safe compounds for functional foods and medicines have become a hot research spot.

The conventional solvent extraction has been used as a classical extraction of polysaccharides. High temperature and long extraction time, the main disadvantages of conventional solvent extraction ${ }^{7}$, can cause the degradation of polysaccharides and the decrease of the harmacological activity of polysaccharides. Compared with conventional solvent extraction, ultrasound-assisted extraction has become a better extraction method due to its advantages, such as low energy and solvent consumption (no reflux or refrigeration are needed), high efficiency and high level of automation. Recently, the application of ultrasound-assisted extraction in analyzing trace organic compounds from soil, animal and plant tissues has been widely reported ${ }^{8-11}$. High efficient extraction by ultrasound maybe ascribed to acoustic cavitation, which could cause the disruption of the cell walls, the reduction of the particle size and the enhancement on contact between solvent and targeted compounds ${ }^{12}$.

Response surface methodology, a statistical-mathematical method, which was originally described by Box and Wilson in 1951, is an effective tool to optimize the process. Response surface methodology usually uses an experimental design such as central-composite rotatory design to fit an empirical, full second-order polynomial model. The main advantage of response surface methodology is to reduce the number of experimental trials needed to evaluate multiple variables, therefore, it is less laborious and time-consuming than other approaches ${ }^{13}$. Response surface methodology is widely applied in the food industry to determine the effects of several variables and optimize their conditions ${ }^{14-17}$.

The aim of the present work is to optimize the conditions for ultrasound-assisted extraction of polysaccharides from 
mulberry leaves. The effects of extraction temperature, power of ultrasound, extraction time and ratio of water to raw material are also studied by response surface methodology on the extraction yield of polysaccharides.

\section{EXPERIMENTAL}

Mulberry leaves were provided by Huzhou Daybreak Import \& Export Co., Ltd., in Huzhou, China. All samples (mulberry leaves) were ground with a disintegrator to obtain a particle size less than $0.4 \mathrm{~mm}$, then defatted with petroleum ether and pretreated with $80 \%$ ethanol twice to remove some colored materials, oligosaccharides and some small molecule materials before the experiment. All chemicals used were analytical grade unless otherwise specified.

Ultrasound-assisted extraction experiments were carried out in ultrasonic cleaning baths produced by Kunshan ultrasound instrument Co., Ltd., in Suzhou, China. It could operate at frequencies ranging from 20 to $99 \mathrm{kHz}$.

Ultrasound-assisted extraction of polysaccharides from mulberry: The ultrasound-assisted extraction procedure used in the experiment was developed by $\mathrm{Wu}$ et al. ${ }^{18}$ with a little modification. The pretreated dry powder $(10 \mathrm{~g})$ was extracted with distilled water [ratio of water to raw material $(\mathrm{mL} / \mathrm{g})$ ranging from $5: 1$ to $25: 1]$ at the power of ultrasound ranging from 40 to $80 \mathrm{~W}$, while the temperature of the water bath ranged from 40 to $80{ }^{\circ} \mathrm{C}$. The water-raw slurry in a stainless steel boiler in the water bath was stirred with an electric mixing paddle for a given time (extraction time ranging from 15 to $30 \mathrm{~min}$ ) during the entire extraction process. Debris fragments of polysaccharides extracts were removed by centrifugation. Protein was removed with Sevag method. The polysaccharides solution was concentrated with a rotary evaporator and precipitated with four volumes of $95 \%$ ethanol for $48 \mathrm{~h}$ at $4{ }^{\circ} \mathrm{C}$. The precipitates were collected by centrifugation $(6000$ $\mathrm{rpm}, 0.5 \mathrm{~h}$ ), washed with acetone and then dried under reduced pressure at $-40{ }^{\circ} \mathrm{C}$ to get crude polysaccharides. All experiments were performed at least in duplicate.

Conventional solvent extraction of polysaccharides from mulberry: $10 \mathrm{~g}$ of ground powder was mixed with 250 $\mathrm{mL}$ of distilled water in a $500 \mathrm{~mL}$ round bottom flask fitted with a cooling system. Extractions were carried out at $80{ }^{\circ} \mathrm{C}$ for 30, 60, $90 \mathrm{~min}$, respectively. The following processes were similar to the ultrasound-assisted extraction of polysaccharides.

Analytical methods: The yield of crude polysaccharides was calculated as a percentage of the weight of the pretreated dry mulberry powder. The total sugar content was determined by the phenol-sulfuric acid method using D-glucose as the standard $^{19}$. The protein content was determined using Kjeldahl Nitrogen Determination method (Kjeldahl, Foss. Tecator) with a conversion factor of 6.25. Moisture content was determined by drying at $105{ }^{\circ} \mathrm{C}$ to constant mass. Ash content was determined by weight difference after calcining samples. Fat content was determined using a Soxhlet apparatus with the official method of AOAC.

The treated samples in conventional solvent extraction or ultrasound-assisted extraction were placed into a preparation chamber, which was attached to a scanning electron microscope (Philips XL 30 ESEM, England). The samples were sputter coated with a thin layer of conductive gold. The shape and the surface characteristics of the samples were magnified and digitally recorded. The crude polysaccharides were purified by a DEAE- 52 cellulose column $(16 \times 200 \mathrm{~mm})$ and characterized by FT-IR spectrum (Thermo Nicolet nexus, USA) to detect functional groups.

Response surface methodology: The interaction effects of extraction temperature, power of ultrasound, extraction time and ratio of water to raw material were studied by response surface methodology. A central-composite rotatory design (CCRD) with four variables at 5 level $\mathrm{s}^{20}$ was designed by SAS (SAS version 9.1, SAS Institute Inc., USA). The variables were coded according to eqn. 1 :

$$
\mathrm{x}_{\mathrm{i}}=\frac{\mathrm{X}_{\mathrm{i}}-\mathrm{X}_{0}}{\Delta \mathrm{X}_{\mathrm{i}}}
$$

where $\mathrm{x}_{\mathrm{i}}$ was the independent variable coded value, $\mathrm{X}_{\mathrm{i}}$ was the independent variable real value, $\mathrm{X}_{0}$ was the independent variable real value on the centre point and $\Delta X_{i}$ was the step change value. Based on the preliminary single-factor experiment results, the selected independent variables and their levels were presented in Table-1. The whole design (Table-2) consisted of 31 experimental points carried out in random order, which included 16 factorial points, 7 centre points and 8 axial points.

Statistical analysis: Experimental data were fitted to a second-order polynomial model and regression coefficients were obtained. The second-order polynomial model for predicting the optimum point was expressed according to the eqn. 2 :

$$
Y=\beta_{0}+\sum_{\mathrm{i}=1}^{4} \beta_{\mathrm{i}} \mathrm{X}_{\mathrm{i}}+\sum_{\mathrm{i}=1}^{4} \beta_{\mathrm{ii}} \mathrm{X}_{\mathrm{i}}^{2}+\sum \sum_{\mathrm{i}<\mathrm{j}=1}^{4} \beta_{\mathrm{ij}} \mathrm{X}_{\mathrm{i}} \mathrm{X}_{\mathrm{j}}
$$

where $Y$ was the response function, $\beta_{0}$ was the centre point of the system, $\beta_{\mathrm{i}}, \beta_{\mathrm{ii}}$ and $\beta_{\mathrm{ij}}$ represented the coefficients of the linear, quadratic and interactive terms, respectively; $X_{\mathrm{i}}, \mathrm{X}_{\mathrm{ii}}$ and $\mathrm{X}_{\mathrm{i}} \mathrm{X}_{\mathrm{j}}$ represented the linear, quadratic and interactive terms of the coded independent variables, respectively. The fitted polynomial equation was expressed as response surface and contour plots in order to visualize the relationship between the response and experimental levels of each factor and to deduce the optimum conditions ${ }^{21}$.

Regression analysis of the data and estimation of the coefficients of the regression equation were analyzed by SAS (SAS version 9.1, SAS Institute Inc., USA). The Design Expert package (Version 7.1.1, 2007, Stat-Ease, Minneapolis, MN, USA) was used to generate three-dimensional response surface and two-dimensional contour plots.

\section{TABLE-1}

RANGE OF INDEPENDENT VARIABLES AND THEIR CORRESPONDING LEVELS

\begin{tabular}{lccccccc}
\hline \multirow{2}{*}{ Independent variable } & \multicolumn{2}{c}{ Symbol } & \multicolumn{5}{c}{ Coded factor level } \\
\cline { 2 - 8 } & Uncoded Coded & -2 & -1 & 0 & +1 & +2 \\
\hline Extraction temp. $\left({ }^{\circ} \mathrm{C}\right)$ & $\mathrm{X}_{1}$ & $\mathrm{x}_{1}$ & 40 & 50 & 60 & 70 & 80 \\
Power of ultrasound $(\mathrm{W})$ & $\mathrm{X}_{2}$ & $\mathrm{x}_{2}$ & 40 & 50 & 60 & 70 & 80 \\
Extraction time (min) & $\mathrm{X}_{3}$ & $\mathrm{x}_{3}$ & 10 & 15 & 20 & 25 & 30 \\
Ratio of water to raw & $\mathrm{X}_{4}$ & $\mathrm{x}_{4}$ & $5: 1$ & $10: 1$ & $15: 1$ & $20: 1$ & $25: 1$ \\
material $(\mathrm{mL} / \mathrm{g})$ & & & & & & & \\
\hline
\end{tabular}




\begin{tabular}{|c|c|c|c|c|c|}
\hline \multirow{3}{*}{ Run } & \multicolumn{5}{|c|}{$\begin{array}{c}\text { TABLE-2 } \\
\text { CENTRAL COMPOSITE ROTATABLE } \\
\text { DESIGN (CCRD) AND RESPONSE }{ }^{\mathrm{A}}\end{array}$} \\
\hline & \multicolumn{4}{|c|}{ Independent variables $^{\mathrm{b}}$} & \multirow{2}{*}{$\operatorname{Response}^{\mathrm{c}}(\%) \mathrm{Y}$} \\
\hline & $\mathrm{x}_{1}$ & $\mathrm{x}_{2}$ & $\mathrm{X}_{3}$ & $\mathrm{X}_{4}$ & \\
\hline 1 & -1 & -1 & -1 & -1 & 3.06 \\
\hline 2 & -1 & -1 & -1 & 1 & 7.39 \\
\hline 3 & -1 & -1 & 1 & -1 & 4.60 \\
\hline 4 & -1 & -1 & 1 & 1 & 4.59 \\
\hline 5 & -1 & 1 & -1 & -1 & 3.72 \\
\hline 6 & -1 & 1 & -1 & 1 & 3.65 \\
\hline 7 & -1 & 1 & 1 & -1 & 5.87 \\
\hline 8 & -1 & 1 & 1 & 1 & 3.30 \\
\hline 9 & 1 & -1 & -1 & -1 & 7.49 \\
\hline 10 & 1 & -1 & -1 & 1 & 9.90 \\
\hline 11 & 1 & -1 & 1 & -1 & 7.37 \\
\hline 12 & 1 & -1 & 1 & 1 & 7.45 \\
\hline 13 & 1 & 1 & -1 & -1 & 7.55 \\
\hline 14 & 1 & 1 & -1 & 1 & 7.31 \\
\hline 15 & 1 & 1 & 1 & -1 & 9.40 \\
\hline 16 & 1 & 1 & 1 & 1 & 7.03 \\
\hline 17 & -2 & 0 & 0 & 0 & 3.29 \\
\hline 18 & 2 & 0 & 0 & 0 & 10.99 \\
\hline 19 & 0 & -2 & 0 & 0 & 6.51 \\
\hline 20 & 0 & 2 & 0 & 0 & 5.94 \\
\hline 21 & 0 & 0 & -2 & 0 & 3.79 \\
\hline 22 & 0 & 0 & 2 & 0 & 4.52 \\
\hline 23 & 0 & 0 & 0 & -2 & 5.96 \\
\hline 24 & 0 & 0 & 0 & 2 & 6.79 \\
\hline 25 & 0 & 0 & 0 & 0 & 7.46 \\
\hline 26 & 0 & 0 & 0 & 0 & 8.33 \\
\hline 27 & 0 & 0 & 0 & 0 & 8.13 \\
\hline 28 & 0 & 0 & 0 & 0 & 8.18 \\
\hline 29 & 0 & 0 & 0 & 0 & 7.81 \\
\hline 30 & 0 & 0 & 0 & 0 & 7.90 \\
\hline 31 & 0 & 0 & 0 & 0 & 7.93 \\
\hline
\end{tabular}

${ }^{\mathrm{a}}$ Non-randomized; ${ }^{\mathrm{b}} \mathrm{Coded}$ symbols and levels of independent variables refer to Table-1; ${ }^{\mathrm{C}}$ Average of duplicated determination from different experiments.

\section{RESULTS AND DISCUSSION}

Fitting the models: Regression analysis was carried out to match the mathematical model with the experimental data, aiming at an optimum region for the responses. Some insignificant terms $\left(\mathrm{x}_{3}, \mathrm{x}_{4}, \mathrm{x}_{1} \mathrm{x}_{2}, \mathrm{x}_{1} \mathrm{x}_{3}, \mathrm{x}_{1} \mathrm{x}_{4}\right)$ were neglected and the predicted model was not refitted. The regression model for polysaccharides extraction (Y) was predicted by eqn. 3 as follows:

$$
\begin{gathered}
\mathrm{Y}=7.962857+1.780375 \mathrm{x}_{1}-0.215458 \mathrm{x}_{2}-0.163121 \mathrm{x}_{1}{ }^{2}- \\
0.391871 \mathrm{x}_{2}^{2}-0.909371 \mathrm{x}_{3}{ }^{2}-0.354371 \mathrm{x}_{4}{ }^{2}+0.450563 \mathrm{x}_{2} \mathrm{X}_{3}- \\
0.754437 \mathrm{x}_{2} \mathrm{X}_{4}-0.705688 \mathrm{x}_{3} \mathrm{x}_{4}
\end{gathered}
$$

The results of analysis of variance (ANOVA) for the CCRD were shown in Table-3. It was obvious that the linear terms except $\beta_{3}$ and $\beta_{4}$, all quadratic terms and the crossproduct terms except $\beta_{12}, \beta_{13}$ and $\beta_{14}$ were significant $(\mathrm{p}<0.01$ or $\mathrm{p}<0.05$ ). The results demonstrated that the effects of extraction temperature and power of ultrasound were the major contributing factors to the yield of polysaccharides.

Table- 4 showed the results of analysis of variance (ANOVA) for the CCRD. From Table-4, we found that the coefficient of determination $\left(\mathrm{R}^{2}\right)$ was 0.9804 . This implied that $98.04 \%$ of

\begin{tabular}{|c|c|c|c|c|}
\hline \multicolumn{5}{|c|}{$\begin{array}{c}\text { TABLE-3 } \\
\text { SIGNIFICANCE OF REGRESSION COEFFICIENTS } \\
\text { OF THE FITTED SECOND-ORDER POLYNOMIAL } \\
\text { MODEL FOR RESPONSE (Y) }\end{array}$} \\
\hline Term & $\begin{array}{l}\text { Regression } \\
\text { coefficients }\end{array}$ & Standard error & t-Value & $p$-Value \\
\hline$\beta_{0}$ & 7.962857 & 0.150288 & 52.98 & $<0.0001^{* * *}$ \\
\hline \multicolumn{5}{|c|}{ Linear } \\
\hline$\beta_{1}$ & 1.780375 & 0.081165 & 21.94 & $<0.0001 * * *$ \\
\hline$\beta_{2}$ & -0.215458 & 0.081165 & -2.65 & $0.0173 *$ \\
\hline$\beta_{3}$ & 0.042042 & 0.081165 & 0.52 & 0.6116 \\
\hline$\beta_{4}$ & 0.133708 & 0.081165 & 1.65 & 0.1190 \\
\hline \multicolumn{5}{|c|}{ Quadratic } \\
\hline$\beta_{11}$ & -0.163121 & 0.074357 & -2.19 & $0.0434 *$ \\
\hline$\beta_{22}$ & -0.391871 & 0.074357 & -5.27 & $<0.0001^{* * *}$ \\
\hline$\beta_{33}$ & -0.909371 & 0.074357 & -12.23 & $<0.0001 * * *$ \\
\hline$\beta_{44}$ & -0.354371 & 0.074357 & -4.77 & $0.0002^{* *}$ \\
\hline \multicolumn{5}{|c|}{ Cross product } \\
\hline$\beta_{12}$ & 0.136812 & 0.099406 & 1.38 & 0.1877 \\
\hline$\beta_{13}$ & -0.096937 & 0.099406 & -0.98 & 0.3440 \\
\hline$\beta_{14}$ & -0.111938 & 0.099406 & -1.13 & 0.2767 \\
\hline$\beta_{23}$ & 0.450563 & 0.099406 & 4.53 & $0.0003 * *$ \\
\hline$\beta_{24}$ & -0.754437 & 0.099406 & -7.59 & $<0.0001 * * *$ \\
\hline$\beta_{34}$ & -0.705688 & 0.099406 & -7.10 & $<0.0001 * * *$ \\
\hline
\end{tabular}
the variations could be explained by the fitted model. Joglekar and $\mathrm{May}^{22}$ suggested that, for a good fit of a model, $\mathrm{R}^{2}$ should

\begin{tabular}{lcccccc}
\multicolumn{7}{c}{ TABLE-4 } \\
\multicolumn{7}{c}{$\begin{array}{c}\text { ANALYSIS OF VARIANCE (ANOVA) OF THE REGRESSION } \\
\text { PARAMETERS FOR THE RESPONSE SURFACE MODEL }\end{array}$} \\
\hline Regression & $\begin{array}{c}\text { Degree of } \\
\text { freedom }\end{array}$ & $\begin{array}{c}\text { Sum of } \\
\text { squares }\end{array}$ & $\mathrm{R}^{2}$ & F-Value & $p$-Value \\
\hline Total model $^{\mathrm{a}}$ & 14 & 126.342726 & 0.9804 & 57.08 & $<0.0001$ \\
Linear & 4 & 77.659268 & 0.6026 & 122.80 & $<0.0001$ \\
Quadratic & 4 & 27.710307 & 0.2150 & 43.82 & $<0.0001$ \\
Crossproduct & 6 & 20.973150 & 0.1627 & 22.11 & $<0.0001$ \\
Error & 16 & 2.529699 & 0.1581 & - & - \\
\hline
\end{tabular}

${ }^{a}$ The coefficient of determination $\left(\mathrm{R}^{2}\right)$ of the predicted model was 0.9804

be at least 0.80 . The significance of each coefficient was also determined by the F-value and $p$-value ${ }^{22}$. The corresponding variables would be more significant if the absolute F-value became greater and $p$-value became smaller ${ }^{23}$. The $p$-value of the regression model was less than 0.0001 . Therefore, the developed model could adequately represent the real relationships among the chosen parameters.

Effects of independent variables on responses: The main goal of response surface methodology was to obtain the optimum values of the independent variables efficiently so that the responses were maximized. Response surface methodology could also identify interactions of the chosen variables by three-dimensional response surface and two-dimensional contour plots. Two kinds of figures were graphical representations of the regression model eqn. 3. In one three-dimensional response surface or two-dimensional contour plots, two variables were depicted while the other two were kept constant.

Figs. 1 to 3 showed the interaction effects of extraction temperature and three other variables (power of ultrasound, extraction time and ratio of water to raw material) on the yield of polysaccharides. Extraction temperature displayed a significant linear effect on the response and the yield of 
polysaccharides increased with increasing extraction temperature. All other variables of the three figures excerted quadratic effects on the response. When extraction temperature was fixed at $60{ }^{\circ} \mathrm{C}$ in Fig. 1, the yield of polysaccharides increased with increasing power of ultrasound. It reached the peak near the central condition of power of ultrasound and then declined. The effects of extraction time (Fig. 2) and ratio of water to raw material (Fig. 3) on the yield of polysaccharides were similar to power of ultrasound in Fig. 1. The general form of three-dimensional relationship demonstrated that the changes of extraction temperature had more significant effect on the yield of polysaccharides than those of three other varaiables (power of ultrasound, extraction time and ratio of water to raw material). The results were in accordance with Table-3.

Figs. 4 and 5 showed the interaction effects of extraction time and two other variables (power of ultrasound and ratio of water to raw material) on the yield of polysaccharides. Quadratic effects for all variables on the response could be observed in two figures. The optimum yield of polysaccharides was obtained when the levels of the three variables were approximately at coded zero level.
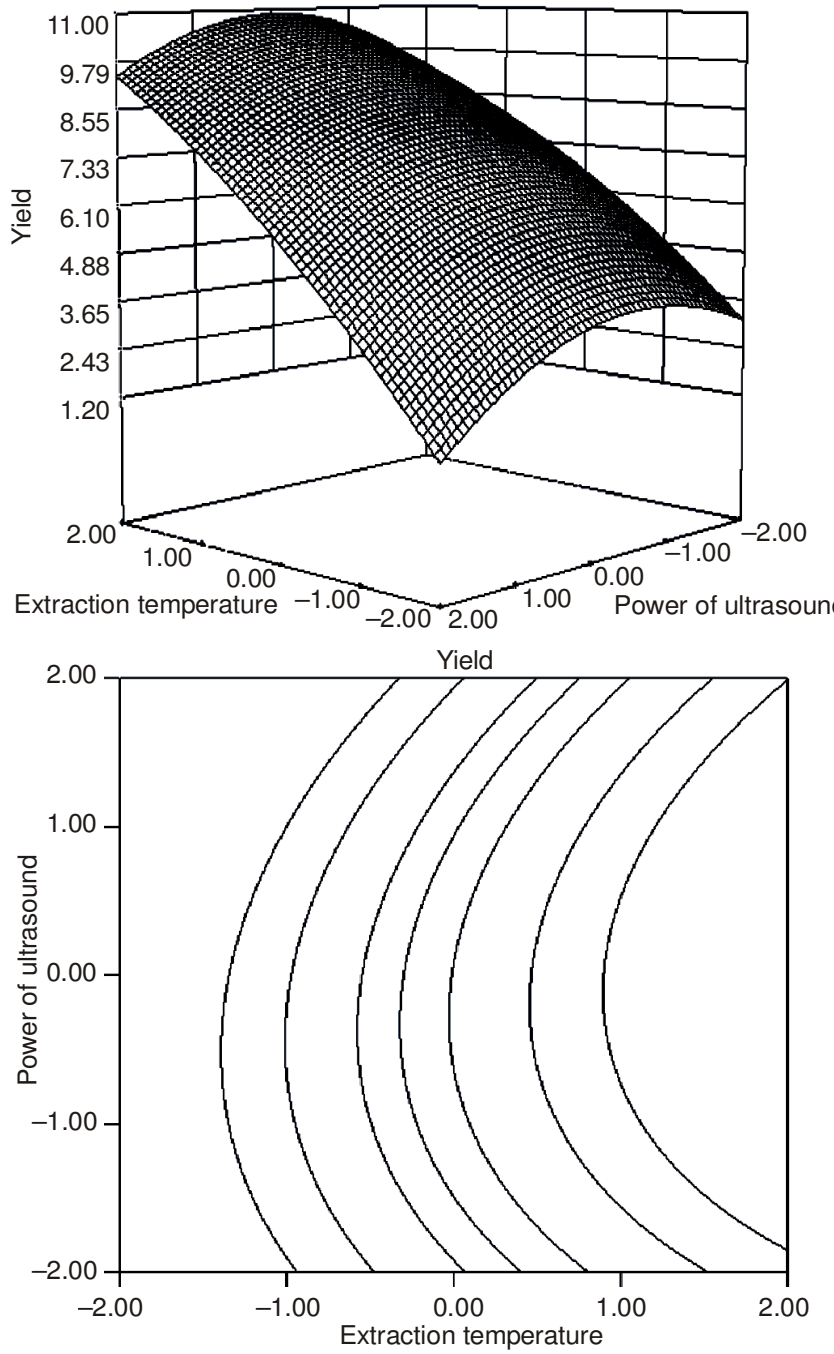

Fig. 1. Response surface (3D) and contour plots for the effects of extraction temperature and power of ultrasound on the yield of polysaccharides
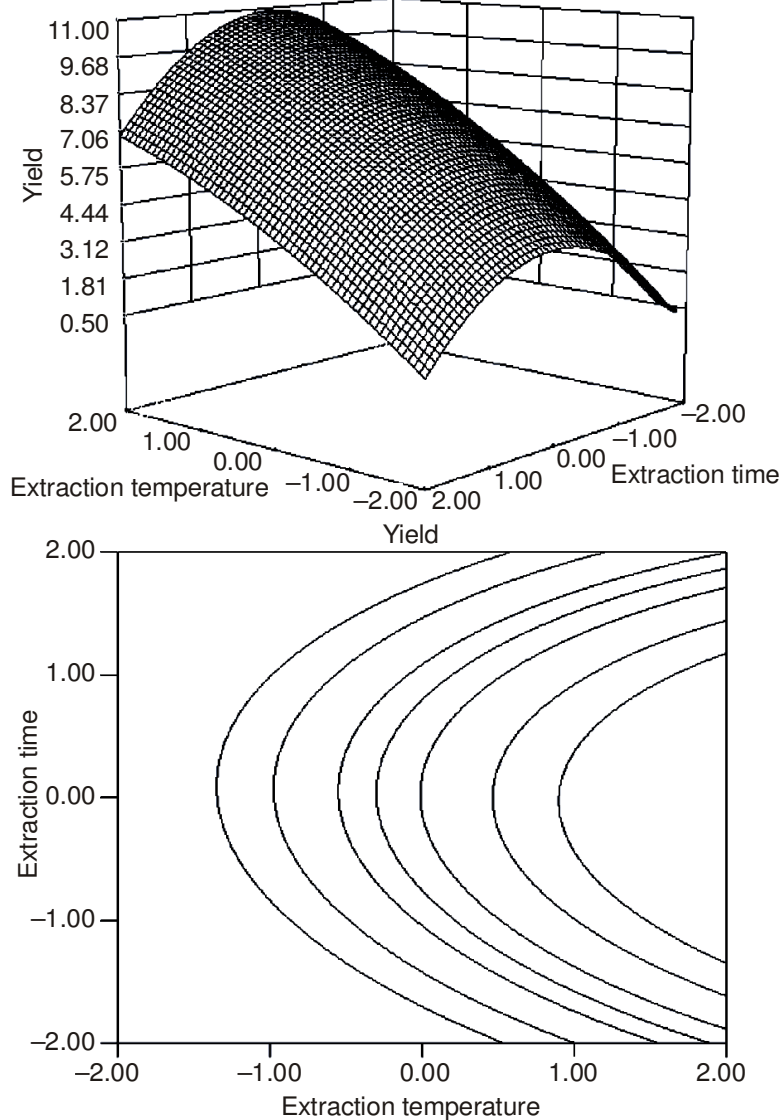

Fig. 2. Response surface (3D) and contour plots for the effects of extraction temperature and extraction time on the yield of polysaccharides
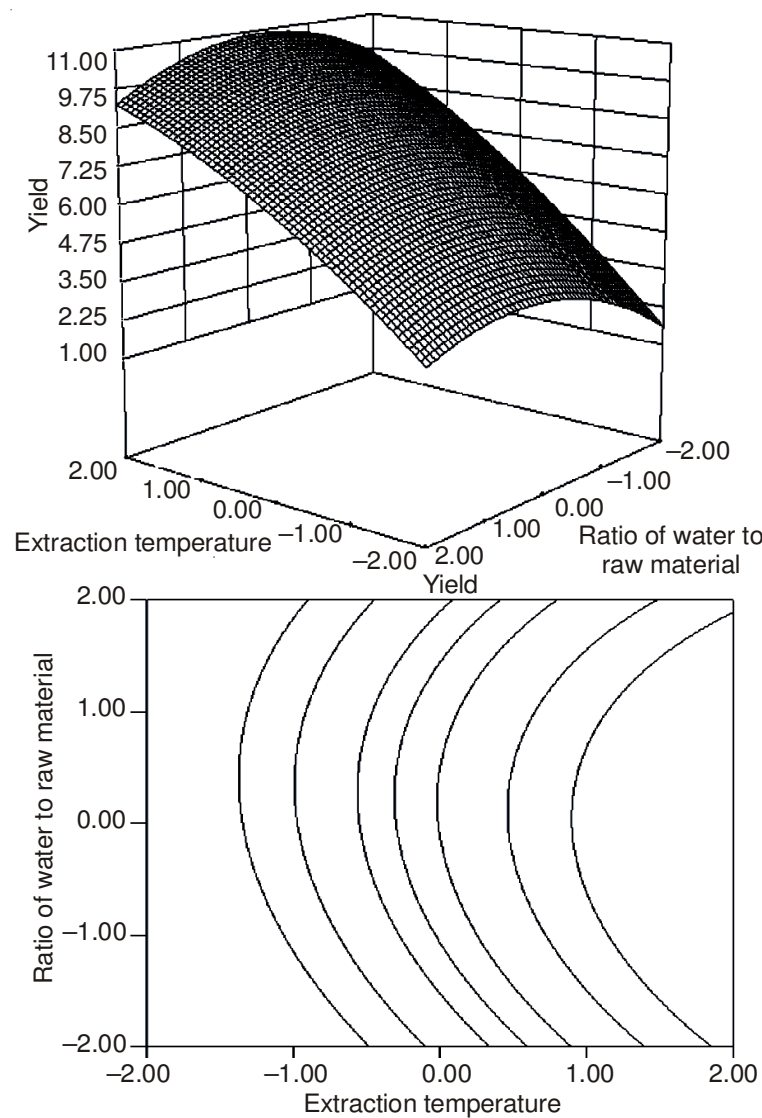

Fig. 3. Response surface (3D) and contour plots for the effects of extraction temperature and ratio of water to raw material on the yield of polysaccharides 
When extraction time was fixed at 20 min in Fig. 4, the yield of polysaccharides increased obviously, reached the optimum value and then decreased slowly with increasing power of ultrasound. It was well known that the powerful ultrasound could induce chemical effect ${ }^{24}$. The cavitation which occurred in water yielded hydroxyl radicals, leading to chemical decomposition ${ }^{25}$. More chemical decomposition occured with stronger power of ultrasound. So we believed that more chemical decomposition was responsible for the decreasing yield of polysaccharides. Under power of ultrasound $60 \mathrm{~W}$, the yield of polysaccharides also increased with increasing extraction time and then decreased after it reached the peak. More chemical decomposition of polysaccharides occured as the extraction time prolonged which caused the decrease of the yield. Similar results were obtained in Fig. 5.

Fig. 6 showed response surface and contour plots of the interaction of extraction time and power of ultrasound on the yield of polysaccharides. The power of ultrasound displayed a linear increase on the response, demonstrating that the yield of the polysaccharides increased with increasing power of ultrasound at fixed ratio of water to raw material. The effect of ratio of water to raw material on the yield of polysaccharides was similar to that of power of ultrasound. Fig. 6 showed that larger ratio of water to raw material and weaker power of ultrasound led to larger response. The optimum response was obtained when the ratio of water to raw material was 25:1 and power of ultrasound was $40 \mathrm{~W}$.
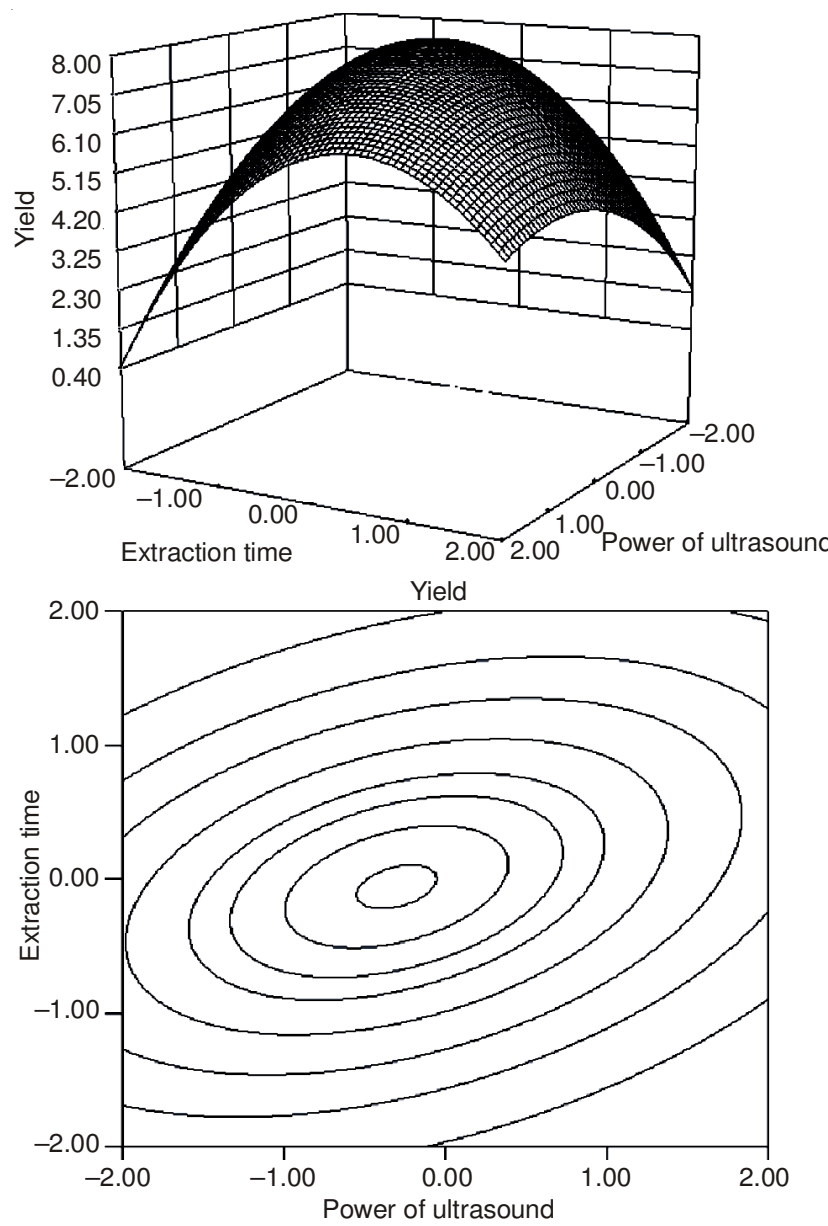

Fig. 4. Response surface (3D) and contour plots for the effects of extraction time and power of ultrasound on the yield of polysaccharides
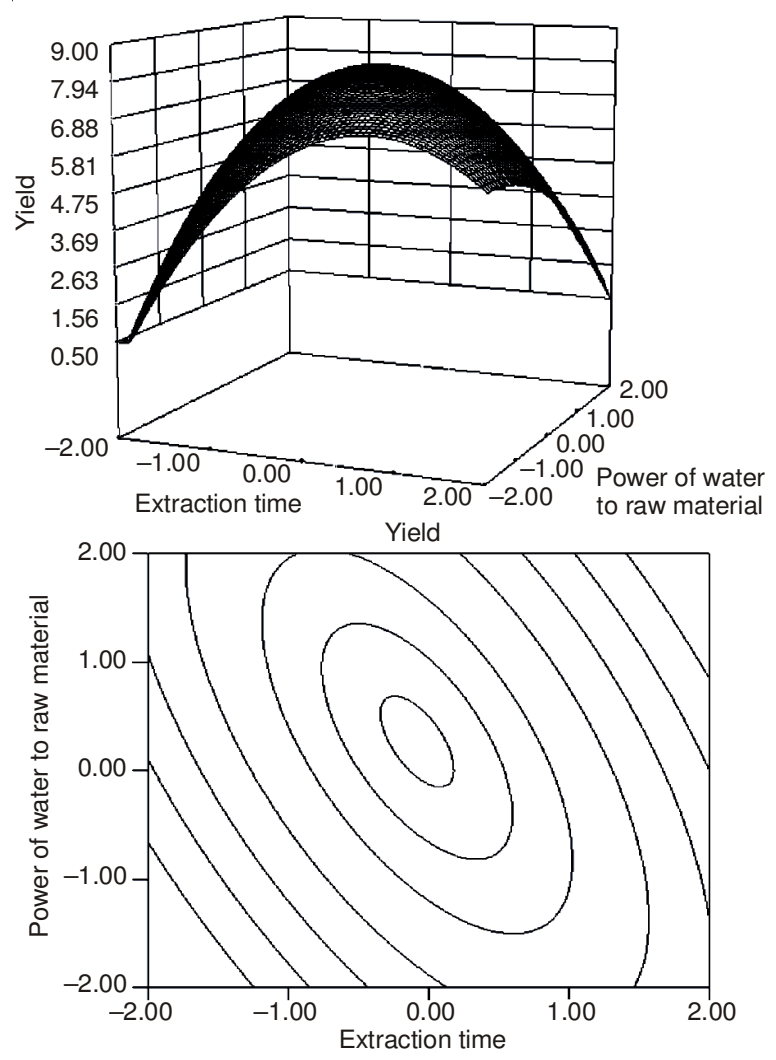

Fig. 5. Response surface (3D) and contour plots for the effects of extraction time and ratio of water to raw material on the yield of polysaccharides

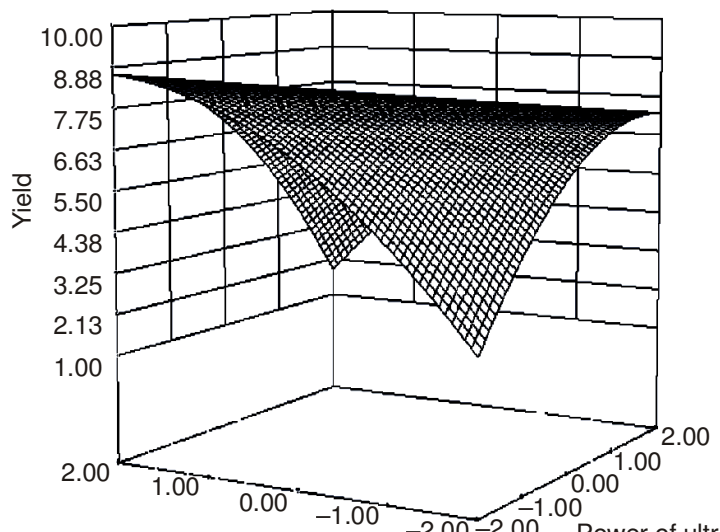

Ratio of water to raw material $-2.00-2.00$ Power of ultrasound

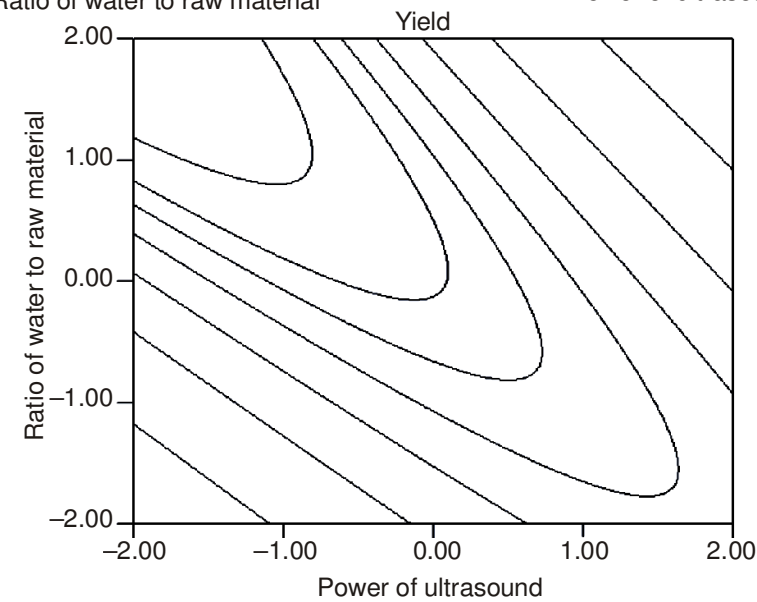

Fig. 6. Response surface (3D) and contour plots for the effects of power of ultrasound and ratio of water to raw material on the yield of polysaccharides 
Verification of results: Based on all the 31 experimental data for extraction of polysaccharides from mulberry leave with ultrasound-assisted extraction, the optimal process was found to be: $\mathrm{x}_{1}=79.92^{\circ} \mathrm{C}$ (extraction temperature), $\mathrm{x}_{2}=61.12$ $\mathrm{W}$ (power of ultrasound), $\mathrm{x}_{3}=20 \mathrm{~min}$ (extraction time), $\mathrm{x}_{4}=$ 14.31:1 (ratio of water to raw material). The model predicted the yield of polysaccharides could be $10.88 \%$. For convenience, the optimum parameters were taken as follows: $\mathrm{x}_{1}=$ $80{ }^{\circ} \mathrm{C}$ (extraction temperature), $\mathrm{x}_{2}=60 \mathrm{~W}$ (power of ultrasound), $x_{3}=20 \mathrm{~min}$ (extraction time), $x_{4}=15: 1$ (ratio of water to raw material). In order to confirm the fit of the predicted and actual data, three parallel experiments were carried out under the condition above and showed an average yield of $10.79 \%$, which was reasonably close to the predicted value and was regarded as satisfactory under the current constraints of experiments. The crude polysaccharides extracted under the optimum conditions were further analyzed for chemical compositions. We found the crude polysaccharides contained $55.06 \%$ total sugar, $14.02 \%$ protein, $14.49 \%$ moisture and $17.48 \%$ ash.

Comparison of ultrasound-assisted extraction to conventional solvent extraction of polysaccharides from mulberry leaves: Under the same extraction temperature, particle size and ratio of water to raw material, the yield of polysaccharides from ultrasound-assisted extraction was compared with that obtained from conventional solvent extraction. The results were presented in Table-5. From Table-5, we found that ultrasound-assisted extraction showed larger yield of polysaccharides and shorter extraction time than conventional solvent extraction. It was well known that ultrasound in ambient fluids could induce the expansion and collapse of cavities near the cell walls, the turbulent vibration on the solvent-solid interfaces and the furious agitation of extraction solvent. These physical phenomenons facilitated the disruption of cell walls, the release of the targeted components and the diffusion of the targeted components into extraction solvent. Therefore, the yield of polysaccharides was improved significantly ${ }^{26}$. Similar result was reported by researchers, while studying the effect of ultrasound on extraction from vegetable tissues ${ }^{27}$.

\begin{tabular}{lcc} 
TABLE 5 \\
$\begin{array}{l}\text { COMPARISON OF OPTIMUM BETWEEN ULTRASOUND- } \\
\text { ASSISTED EXTRACTION AND CONVENTIONAL } \\
\text { SOLVENT EXTRACTION }\end{array}$ \\
\hline \multicolumn{1}{c}{ Method } & $\begin{array}{c}\text { Conventional } \\
\text { solvent extraction }\end{array}$ & $\begin{array}{c}\text { Ultrasound-assisted } \\
\text { extraction }\end{array}$ \\
\hline $\begin{array}{l}\text { Extraction temp. }\left({ }^{\circ} \mathrm{C}\right) \\
\text { Power of ultrasound }(\mathrm{W})\end{array}$ & 80 & 80 \\
$\begin{array}{l}\text { Extraction time (min) } \\
\text { Ratio of water to raw } \\
\text { material }(\mathrm{mL} / \mathrm{g})\end{array}$ & - & 60 \\
Yield $(\%)$ & $15: 1$ & 20 \\
\hline
\end{tabular}

FT-IR spectra: The polysaccharides were analyzed using by FT-IR to detect functional groups (Fig. 7). The relatively strong absorption peak at around $1650 \mathrm{~cm}^{-1}$, the weak one at around $1250 \mathrm{~cm}^{-1}$ and the other two between 1100 and 1010 $\mathrm{cm}^{-1}$ indicated the characteristic bands of polysaccharides. The intense peak at $3425 \mathrm{~cm}^{-1}$ was $-\mathrm{OH}$ stretching peak and the band at around $2930 \mathrm{~cm}^{-1}$ was $\mathrm{C}-\mathrm{H}$ stretching vibration ${ }^{28,29}$.
The weak peak at $2368 \mathrm{~cm}^{-1}$ was $\mathrm{C}-\mathrm{H}$ transiting angle peak. The carbonyl $(\mathrm{C}=\mathrm{O})$ stretching was at 1741 and $1614 \mathrm{~cm}^{-1}$. The bands at 1325 and $1242 \mathrm{~cm}^{-1}$ were indication of ring breathing with C-O strecthing ${ }^{30}$. The peak at $1242 \mathrm{~cm}^{-1}$ was unsymmetrical carbonyl stretching peak. The $1200-1000 \mathrm{~cm}^{-1}$ region, referred to as the "finger print" region, was unique to a sample. The two obvious absorptions between 1100 and 1010 $\mathrm{cm}^{-1}$ were originated from the glycosidic linkage $\mathrm{v}(\mathrm{C}-\mathrm{O}-\mathrm{C})$, indicating the stretching vibration of furanose. A characteristic absorption at $920 \mathrm{~cm}^{-1}$ was observed, indicating the existence of $\alpha$-D-glucan ${ }^{31}$.

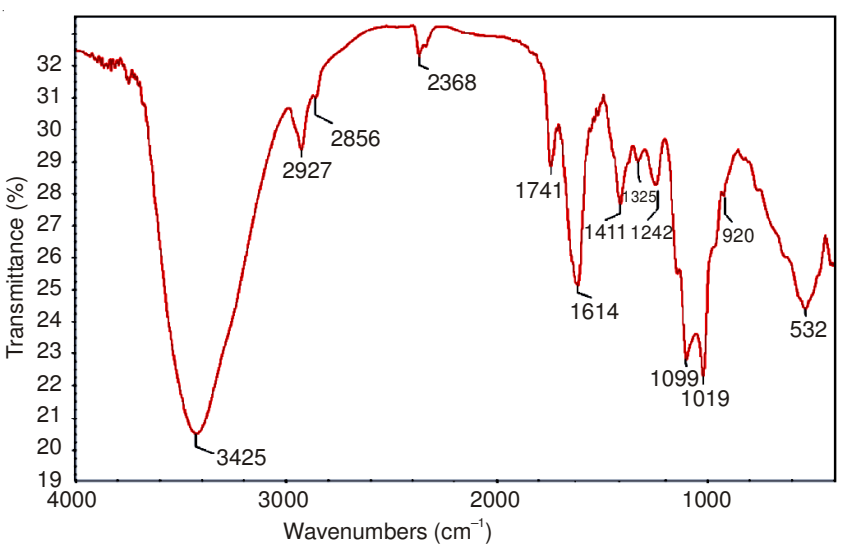

Fig. 7. FT-IR spectrum of the polysaccharides from mulberry leaves

\section{Conclusion}

Response surface methodology was effective for estimating the effects of four independent variables on the yield of polysaccharides. Using response surface methodology and contour plots, the optimum set of the independent variables was obtained graphically to get the desired levels of ultrasoundassisted extraction of polysaccharides. Optimum conditions (extraction temperature $80{ }^{\circ} \mathrm{C}$, power of ultrasound $60 \mathrm{~W}$, extraction time $20 \mathrm{~min}$ and ratio of water to raw material 15:1) for the extraction procedure of polysaccharides from mulberry leaves were identified. Under the optimum conditions, the yield of polysaccharides was $10.79 \%$. Compared to conventional solvent extraction, ultrasound-assisted extraction reduced extraction time and gave a larger yield of polysaccharides due to the acoustic cavitation of ultrasound-assisted extraction.

\section{ACKNOWLEDGEMENTS}

Project is supported by the Research Foundation of Health Department of Zhejiang Province, China (No. 2012KYA055).

\section{REFERENCES}

1. S. Ercisli and E. Orhan, Food Chem., 103, 1380 (2007).

2. J. Zhishen, T. Mengcheng and W. Jianming, Food Chem., 64, 555 (1999).

3. T. Katsube, N. Imawaka, Y. Kawano, Y. Yamazaki, K. Shiwaku and Y. Yamane, Food Chem., 97, 25 (2006).

4. N. Asano, T. Yamashita, K. Yasuda, K. Ikeda, H. Kizu, Y. Kameda, A. Kato, R.J. Nash, H.S. Lee and K.S. Ryu, J. Agric. Food Chem., 49, 4208 (2001).

5. F. Wang and J.R. Li, Food Sci., 26, 111 (2005).

6. C.Y. Xue, J.Y. Teng, J.H. Qiu, Y.H. Ou, Z.X. Zheng and R.X. Zhang, Ying Yang Xue Bao, 27, 167 (2005).

7. Z. Hromádková, A. Ebringerová and P. Valachovic, Ultrason. Sonochem., 9, 37 (2002). 
8. A. Tor, M.E. Aydin and S. Özcan, Anal. Chim. Acta, 559, 173 (2006).

9. Z. Hromádková, A. Ebringerová and P. Valachovic, Ultrason. Sonochem., 5, 163 (1999).

10. Z. Hromádková and A. Ebringerová, Ultrason. Sonochem., 10, 127 (2003).

11. L. Paniwnyk, E. Beaufoy, J.P. Lorimer and T.J. Mason, Ultrason. Sonochem., 8, 299 (2001).

12. J. Raso, P. Manas, R. Pagan and F.J. Sala, Ultrason. Sonochem., 5, 157 (1999).

13. G. Lombardi-Boccia, B. Martínez-Domínguez, A. Aguzzi and F. Rincón-León, Food Chem., 78, 505 (2002).

14. S. Levigne, M.C. Ralet and J.F. Thibault, Carbohydr. Polym., 49, 145 (2002).

15. L. Quanhong and F. Caili, Food Chem., 92, 701 (2005).

16. M.S. Tanyildizi, D. Özer and M. Elibol, Process Biochem., 40, 2291 (2005).

17. A. Vohra and T. Satyanarayana, Process Biochem., 37, 999 (2002).

18. J.Y. Wu, L.D. Ling and F.T. Chau, Ultrason. Sonochem., 8, 347 (2001).

19. M. Dubois, K.A. Gilles, J.K. Hamilton, P.A. Rebers and F. Smith, Anal. Chem., 28, 350 (1956).

20. W.G. Cochran and G.M. Cox, Some Methods for the Study of Response Surfaces: In Experimental Designs, Wiley, New York, pp. 335-375 (1992)
21. R. Triveni, T.R. Shamala and N.K. Rastogi, Process Biochem., 36, 787 (2001).

22. A.M. Joglekar and A.T. May, Cereal Foods World., 32, 857 (1987).

23. A.C. Atkinson and A.N. Donev, Optimum Experimental Designs, Oxford University Press, Oxford, pp. 132-189 (1992).

24. S. Koda, T. Kimura, T. Kondo and H. Mitome, Ultrason. Sonochem., 10, 149 (2003).

25. M.M. Castellanos, D. Reyman, C. Sieiro and P. Calle, Ultrason. Sonochem., 8, 17 (2001).

26. S.N. Zhao, K.C. Kwok and H.H. Liang, Sep. Purif. Techmol., 55, 307 (2007).

27. M.A. Rostagno, M. Palma and C.G. Barroso, J. Chromatogr. A, 1012, 119 (2003).

28. X.P. Yang, D.Y. Guo, J.M. Zhang and M.C. Wu, Int. Immunopharmacol., 7, 427 (2007)

29. C.H. Liu, Q.X. Lin, Y. Gao, L. Ye, Y. Xing and T. Xi, Carbohydr. Polym., 67, 313 (2007).

30. R.C. Sun and J. Tomkinson, Ultrason. Sonochem., 9, 85 (2002).

31. J. Sandula, G. Kogan, M. Kacurakova and E. Machova, Carbohydr. Polym., 38, 247 (1999). 